\title{
Prone Positioning Improves Oxygenation and Outcome of Trauma Patients with Severe Acute Respiratory Distress Syndrome (ARDS)
}

Evgeni Brotfain $^{1 * \#}$, Netzah Ben Hur BN ${ }^{1 \#}$, Nancy Boniel ${ }^{2}$, Amit Frenkel ${ }^{1}$, Leonid Koyfman ${ }^{1}$, Alexander Zlotnik ${ }^{1}$ and Moti Klein ${ }^{1}$

${ }^{1}$ Department of Anesthesiology and Critical Care, Soroka Medical Center, Ben-Gurion University of the Negev, Beer Sheva, Israel

${ }^{2}$ Department of Radiology, Soroka Medical Center, Ben-Gurion University of the Negev, Beer Sheva, Israel

\#These two authors contributed equally.

\begin{abstract}
Introduction: The acute respiratory distress syndrome (ARDS) was proposed as an acute onset respiratory failure with $\mathrm{PaO}_{2} / \mathrm{FiO}_{2}$ ratio $<200$ (regardless of positive end-expiratory pressure (PEEP) level), bilateral infiltrates on chest X-ray and pulmonary artery occlusion pressure below $18 \mathrm{mmHg}$. The main therapeutic management of ARDS is based on the concept of protective lung strategy ventilation. Some authors reported about increase in oxygenation in the prone position (PP) in both direct types of ARDS; however, the clinical significance of it still remains questionable. We review and analyze potential clinical benefits of using the prone position in trauma critically ill patients with severe ARDS.

Methods: This is an observational, retrospective study provided in university teaching hospital from January 2006 and June 2012. In this study, we retrospectively examined clinical data of 33 trauma and 56 non-trauma critically ill adult patients suffering from severe ARDS and managed by application of prone positioning (PP) during General Intensive Care Unit (GICU) stay.

Results: We found no difference in demographic data and in the rate of complications between both study groups after application of PP. The trauma patients with severe acute lung injury demonstrated remarkable improvement in lung compliance (from $18.72 \pm 9.52$ to $29.285 \pm 6.26, p<0.05$,) and significant decreases in peak inspiratory pressure (PIP) in the prone position (from $33.48 \pm 9.52 \mathrm{~cm} \mathrm{H} 2 \mathrm{O}$ to $21.06 \pm 7.06 \mathrm{~cm} \mathrm{H} 2 \mathrm{O}, \mathrm{p}<0.05$ ) The mortality rate was lower in trauma group patients treated by PP $(p<0.005)$ than in non-trauma ICU population.
\end{abstract}

Conclusions: Our study showed clinical benefit by application of PP in the treatment of severe ARDS in posttrauma critically ill patients.

Keywords: Prone position; Multiple trauma; Severe ARDS

\section{Introduction}

Acute Respiratory Distress Syndrome (ARDS) was described in 1967 in context of acute dyspnea, severe hypoxemia, decreased lung compliance and bilateral diffuse lung infiltrates on chest radiograph [1]. The first definition of ARDS was proposed in 1994 as an acute onset respiratory failure with $\mathrm{PaO}_{2} / \mathrm{FiO}_{2}$ ratio $<200$ (regardless of PEEP level), bilateral infiltrates on chest X-ray and pulmonary artery occlusion pressure below $18 \mathrm{mmHg}$ [2,3]. Since 2012, ARDS has been defined as an arterial oxygen partial pressure $\left(\mathrm{PaO}_{2}\right)$ to inspiratory oxygen fraction $\left(\mathrm{FiO}_{2}\right)$ ratio less than 200 and PEEP or CPAP $>5 \mathrm{~cm}$ $\mathrm{H}_{2} \mathrm{O}$ according to the American European Consensus Conference (AECC) [4]. The therapeutic management of ARDS has also changed over the last two decades. The cornerstone of therapeutic strategy in ARDS began from a new concept of ventilatory support - "protective lung strategy" - which includes mechanical ventilation with small tidal volumes, low plateau pressure and application of relatively high levels of positive end-expiratory pressure (PEEP) [5-7]. In recent years, inhalation of Nitric Oxide (NO), prone position (PP), high frequency ventilation and ECMO devices have successfully demonstrated their ability to improve oxygenation in critically ill ARDS patients $[8,9]$.

The effectiveness of PP in treatment of severe ARDS patients remains questionable. An increase in oxygenation in the prone position has been demonstrated in both direct (lung contusion, aspiration) and indirect (sepsis, SIRS, burns, pancreatitis) pathophysiological types of ARDS [10]. Previously published data [11,12] demonstrated no significant survival benefit in patients with ARDS or in subgroups of patients with moderate and severe hypoxemia. However, recently published data [13] shows a significant improvement in survival from early application of prone positioning in severe $\left(\mathrm{PO}_{2} \mid \mathrm{FiO}_{2}\right.$ ratio less than 150) ARDS in a mixed general ICU population. Moreover, use of the prone position was demonstrated to provide clinical benefit especially in direct acute lung injury (post-traumatic lung contusion ARDS/acute lung injury- ALI) [14]. In this paper, we review and analyze potential clinical benefits of using the prone position in trauma versus non-trauma types of severe ARDS in critically ill patients admitted to the intensive care unit at Soroka Medical Center.

\section{Patients and Methods}

The study is observational and retrospective. The Human Research and Ethics Committee at Soroka Medical Center in Beer-Sheva, Israel approved this study. We collected clinical data from all cases of critically ill patients suffering from ARDS admitted to the General Intensive Care Unit (GICU) in Soroka Medical Center between January 1999 and June 2005. Soroka Medical Center is a tertiary care facility with 1100 inpatient beds, including 12 beds in the General Intensive Care Unit (GICU). All clinical data was extracted from Patients' Register Database, General Intensive Care Unit, Soroka Medical Center during

*Corresponding author: Evgeni Brotfain, Department of Anesthesiology and Critical Care Soroka Medical Center, Ben Gurion University of the Negev, Beer Sheva, Israel, Tel: +972546218106; E-mail: bem1975@gmail.com

Received September 29, 2014; Accepted December 24, 2014; Published December 27, 2014

Citation: Brotfain E, Hur NBBN, Boniel N, Frenkel A, Koyfman L, et al. (2014) Prone Positioning Improves Oxygenation and Outcome of Trauma Patients with Severe Acute Respiratory Distress Syndrome (ARDS). J Trauma Treat 4: 228. doi:10.4172/2167-1222.1000228

Copyright: @ 2014 Brotfain E, et al. This is an open-access article distributed unde the terms of the Creative Commons Attribution License, which permits unrestricted use, distribution, and reproduction in any medium, provided the original author and source are credited. 
Citation: Brotfain E, Hur NBBN, Boniel N, Frenkel A, Koyfman L, et al. (2014) Prone Positioning Improves Oxygenation and Outcome of Trauma Patients with Severe Acute Respiratory Distress Syndrome (ARDS). J Trauma Treat 4: 228. doi:10.4172/2167-1222.1000228

those six years.

All adult critically ill patients suffering from severe ARDS who were managed by application of Prone Positioning (PP) during GICU admission were included in the present study. According to the admission diagnosis, all severe ARDS patients treated with PP were retrospectively allocated to trauma and non-trauma study groups.

\section{The ARDS criteria and prone positioning protocol}

The criteria of severe ARDS include diffuse patchy infiltrates on chest radiograph, $\mathrm{PaO}_{2} / \mathrm{FiO}_{2}$ ratio less than 100 and (PEEP) of $>10$ $\mathrm{cm} \mathrm{H}_{2} \mathrm{O}$ [4]. All severe ARDS patients were mechanically ventilated on volume or pressure control modes. Prone positioning was applied to critically ill patients with severe ARDS $\left(\mathrm{PaO}_{2} / \mathrm{FiO}_{2}<100, \mathrm{FiO}_{2}=1.0\right)$. Patients were placed back in the supine position when the $\mathrm{PaO}_{2} / \mathrm{FiO}$ ratio had improved to more than 200 and/or $\mathrm{FiO}_{2}$ more than 0.6.

\section{Variables, measures, primary and secondary outcome}

The demographic data, cause for admission, APACHE-II score, patients' co-morbidities, and length of ICU stay, clinical data of oxygenation/ventilation parameters $\left(\mathrm{FiO}_{2}, \mathrm{PaO}_{2} / \mathrm{FiO}_{2}, \mathrm{PaCO}_{2}, \mathrm{PEEP}\right.$ level, lung compliance) and in-ICU mortality were collected. The primary outcome endpoint of the present study is ICU mortality rate. Lung mechanics and oxygenation parameters are the secondary outcomes.

\section{Statistical Analysis}

For categorical variables, proportions were compared using Fisher's Exact Test or Chi Square, as appropriate. Continuous variables were analyzed with Student's $t$-test or the Wilcoxon Rank Sum Test, depending on the validity of the normality assumption (Pearson's chi-squared test). A two-tailed $\mathrm{p}$-value of $<0.05$ was considered to be significant. All analysis was performed using SPSS version 17 (SPSS, Chicago, IL).

\section{Results}

In total, two hundred and ten (210) critically ill patients with ARDS were hospitalized in the General Intensive Care Unit over the six years period (Table 1). Of those 210, 89 patients fulfilled the criteria for severe ARDS $\left(\mathrm{PaO}_{2} / \mathrm{FiO}_{2}<100\right)$. Those patients were ventilated by $\mathrm{FiO}_{2}$ 1.0 and treated by placement in the prone position. Those patients were included in the present study.

Thirty-three 33 patients had admission diagnosis of multiple trauma (Trauma group) and fifty-six patients 56 with admission diagnosis other than trauma were included in Non-trauma group (see an explanation in Table 1).

There was no significant difference in demographic data, APACHE score and probability of death index between trauma and non-trauma population. Patients in both study groups were hemodynamically stable before (Group 1, $81.6 \pm 23.68 \mathrm{mmHg}$ vs Group 2, $82.78 \pm 19.29$ $\mathrm{mmHg}$ ) and after (Group 1, 87.06 $\pm 17.35 \mathrm{mmHg}$ vs Group 2, 87.82 $\pm 17.85 \mathrm{mmHg}$ ) application of PP. The overall complication rate was similar in both study groups $(10 \%, p$ NS, Table 1$)$. The mortality rate was significantly lower in trauma patients after application of PP than in the non-trauma ICU population $(\mathrm{p}<0.005$, Table 1$)$.

The response of oxygenation with the use of prone positioning was similar in both study groups [increase in $\mathrm{PaO}_{2} / \mathrm{FiO}_{2}$ ratio $>200$ from $81.626 \pm 18.376$ (Group 1) and $76.444 \pm 17.398$ (Group 2) after prone position application, $\mathrm{p}$ NS, (Table 2). The PEEP levels were unremarkably changed after PP in trauma (from $9.33 \pm 3.763$ to $7.655 \pm 2.175 \mathrm{mmHg}$ ) and non-trauma (from $9.196 \pm 2.932$ to 8.765 $\pm 2.905 \mathrm{mmHg}$, p NS, (Table 2) persons. However, trauma patients with severe acute lung injury demonstrated remarkable improvement in lung compliance (from $18.72 \pm 9.52$ to $29.285 \pm 6.26$, $\mathrm{p}<0.05$,) and significant decreases in peak inspiratory pressure (PIP) in the prone position (from $33.48 \pm 9.52 \mathrm{~cm} \mathrm{H}_{2} \mathrm{O}$ to $21.06 \pm 7.06 \mathrm{~cm} \mathrm{H}_{2} \mathrm{O}, \mathrm{p}<0.05$ ) (Table 2). Finally, lung compliance was significantly higher in trauma group patients after PP treatment $(29.285 \pm 6.26$ vs $20.428 \pm 6.56)$ than in non-trauma group (Table 2).

PIP after PP treatment declined significantly also in trauma group ( $21.06 \pm 7.06$ vs. $27.127 \pm 8.11 \mathrm{~cm} \mathrm{H}_{2} \mathrm{O}, \mathrm{p}<0.05$, Table 2$)$. Total time in the prone position was higher in trauma group patients $(54 \pm 59.94 \mathrm{~h}$ vs. $34.196 \pm 43.056 \mathrm{~h}, \mathrm{p}<0.005$, Table 2 ). Time on mechanical ventilation and total length of ICU stay after PP management were significantly less in trauma group population than non-trauma persons $(\mathrm{p}<0.05$, Table 2). Injury severity score was similar between survived and nonsurvived trauma patients ( $\mathrm{p}$ NS, Table 2).

\section{Discussion}

Severe ARDS caused by direct (pneumonia, aspiration, traumatic pulmonary contusion, inhalational injury etc.) or indirect (sepsis, severe SIRS etc.) etiologic factors are characterized pathophysiologically by widespread lung and endothelial injuries $[15,16]$. Post-traumatic severe ARDS is primarily related to alveolar and capillary damage by intense direct kinetic force on the thorax as opposed to a systemic inflammatory reaction (SIRS)/sepsis-induced ARDS which develops as a result of increased cytokine blood levels leading to alveolar edema, increased alveolar-capillary permeability, apoptosis and, eventually, cell necrosis $[17,18]$.

Thus, the "pulmonary contusion" in trauma patients with ARDS is a self-limited insult contrary to the systemic inflammatory reaction, which continues progressively, causing on-going indirect lung injury until the severe SIRS or sepsis is successfully managed by the clinicians. In both direct and indirect types of pathophysiological mechanisms of ARDS, the prone positioning improves oxygenation and respiratory mechanics $[19,20]$. Prone positioning provides more homogeneous

\begin{tabular}{|l|c|c|c|}
\hline \multirow{2}{*}{ Age (mean \pm SD) } & Trauma*** & Non-trauma & \multirow{2}{*}{ P value } \\
\cline { 2 - 4 } & $(\mathrm{n}=33)$ & $(\mathrm{n}=56)^{\#}$ & \\
\hline Gender (male/female) & $39.87 \pm 14.66$ & $52.35 \pm 19.22$ & $\mathrm{NS}$ \\
\hline APACHE II score 1 (units) & $12 / 11(33)$ & $30 / 26(56)$ & $\mathrm{NS}$ \\
\hline APACHE II score 2 (units) & $22.38 \pm 6.52$ & $23.92 \pm 7.96$ & $\mathrm{NS}$ \\
\hline Complications rate (overall, $\mathrm{n})^{\star \#}$ & $24.6 \pm 5.77$ & $27 \pm 6.94$ & $\mathrm{NS}$ \\
\hline 3/33 6/56 NS & $3 / 33$ & $6 / 56$ & $\mathrm{NS}$ \\
\hline Mortality rate (\%) & $10 / 33(22.7 \%)$ & $34 / 56(51.1 \%)$ & 0.005 \\
\hline ISS (for trauma patients) & Survivors & Nonsurvivors & P value \\
\cline { 2 - 4 } & $29.4 \pm 9.71$ & $24.086 \pm 9.69$ & NS \\
\hline
\end{tabular}

*APACHE II score 1 was calculated on admission to ICU; APACHE II score 2 was calculated on day when application of Prone Position (PP) has been initiated.

${ }^{* *} P$ value has been considered to be statistically significant if less than 0.05 ; NSnon significant.

${ }^{* * *}$ Multiple trauma injuries included: head injury, blunt chest and abdomen trauma spine and extremity fractures. ISS: Injury Severity Score. \#Non-trauma group patients included several diagnoses on admission to ICU: sepsis/septic shock, acute pancreatitis, pneumonia, blood products transfusion for non-trauma patients, massive intracerebral hemorrhage.

\#Complications on PP were included pressure sores on chest and abdomen surface (totally 9 patients for both study groups, 10\%).

Table 1: Demographic data (mean \pm SD, \%) and clinical outcome endpoints of patients on prone positioning. 
Citation: Brotfain E, Hur NBBN, Boniel N, Frenkel A, Koyfman L, et al. (2014) Prone Positioning Improves Oxygenation and Outcome of Trauma Patients with Severe Acute Respiratory Distress Syndrome (ARDS). J Trauma Treat 4: 228. doi:10.4172/2167-1222.1000228

Page 3 of 4

\begin{tabular}{|c|c|c|c|}
\hline & Trauma $(n=33)$ & Non-trauma $(n=33)$ & $P$ value ${ }^{* *}$ \\
\hline $\mathrm{PaO}_{2} / \mathrm{FiO}_{2}$ before PP (torr) & $81.626 \pm 18.376$ & $76.444 \pm 17.398$ & NS \\
\hline $\mathrm{PaO}_{2} / \mathrm{FiO}_{2}$ after PP (torr) & $200.556 \pm 45.822$ & $200.241 \pm 44.08$ & NS \\
\hline $\mathrm{FiO}_{2}$ before $\mathrm{PP}(\%)$ & $87.57 \pm 18.376$ & $87.41 \pm 17.398$ & NS \\
\hline $\mathrm{FiO}_{2}$ after $\mathrm{PP}(\%)$ & $51.034 \pm 15.199$ & $52.127 \pm 18.1702$ & NS \\
\hline PEEP $\left(\mathrm{cmH}_{2} \mathrm{O}\right)$ before PP & $9.33 \pm 3.763$ & $9.196 \pm 2.932$ & NS \\
\hline PEEP $\left(\mathrm{cmH}_{2} \mathrm{O}\right)$ after PP & $7.655 \pm 2.175$ & $8.765 \pm 2.905$ & NS \\
\hline Compliance $\left(\mathrm{ml} / \mathrm{cmH}_{2} \mathrm{O}\right)$ Before PP & $18.72 \pm 9.52$ & $19.33 \pm 8.48$ & NS \\
\hline Compliance $\left(\mathrm{ml} / \mathrm{cmH}_{2} \mathrm{O}\right)$ After PP & $29.285 \pm 6.26$ & $20.428 \pm 6.56$ & $<0.05$ \\
\hline PIP $\left(\mathrm{cmH}_{2} \mathrm{O}\right)$ before PP & $33.48 \pm 9.52$ & $31.839 \pm 8.48$ & NS \\
\hline $\mathrm{PIP}\left(\mathrm{cmH}_{2} \mathrm{O}\right)$ after PP & $21.06 \pm 7.06$ & $27.127 \pm 8.11$ & $<0.05$ \\
\hline \multicolumn{4}{|l|}{ Prone positioning characteristics } \\
\hline Time on PP (hours) on PP *** (h) & $54 \pm 59.94$ & $34.196 \pm 43.056$ & $<0.005$ \\
\hline Time to improve oxygenation & $8.76 \pm 11.245$ & $8.67 \pm 11.6$ & NS \\
\hline Ventilatory support after PP & $8.98 \pm 13.1$ & $14.9 \pm 16.2$ & $<0.05$ \\
\hline Length of ICU stay after PP (days) & $10.67 \pm 13.155$ & $18.06 \pm 18.75$ & $<0.05$ \\
\hline
\end{tabular}

${ }^{* *} \mathrm{P}$ value has been considered to be statistically significant less than 0.05

***Time of improvement oxygenation $\left(\mathrm{PaO}_{2} / \mathrm{FiO}_{2}\right.$ ratio $>200$ or/and $\left.\mathrm{FiO}_{2}<0.6\right)$ since initiation of prone position

ICU- intensive care unit, PP- prone positioning, PEEP- positive end-expiratory pressure

Table 2: Clinical data of pulmonary parameters (mean $\pm S D, \%$ ) of critically ill patients in the prone position

distribution of transpulmonary pressure and a subsequent decrease in alveolar inflation pressure over the non-dependent (dorsal) and dependent (ventral) lung zones [21,22]. The perfusion in dorsal (dependent) regions is also improved with the use of prone positioning, which may be explained by the effects of gravity. Lung mechanics have been shown to improve after repositioning patients from prone to supine position and such observation is related to increased respiratory system compliance and decreased inspiratory pressure $[23,24]$.

There is some clinical data which shows remarkable improvement in survival of mixed critically ill population after application of PP [13]. However, none of the clinical studies we reviewed showed an increase in survival in homogenic (for example, direct pathophysiological mechanism) critically ill patients with severe ARDS.

In the present study, a remarkable improvement of lung mechanics and survival were showed in trauma patients. Most of them had direct chest injury (pulmonary contusion). It might be a good explanation of consistent potential benefit of prone positioning application after initial self-limited lung injury. In our present study, we argue that the prone positioning application failed to achieve positive constant physiological effects because of continuous indirect lung injury in the non-trauma group.

Despite the potential complications and risks (inability to perform CPR, damage to peripheral nerves and eyes, elevation of intra-abdominal pressure, etc), use of the prone position has been demonstrated to be a safe and beneficial tool, especially in multiple trauma patients [25]. Hale et al. [26] demonstrated safe application of prone positioning in adult burn patients with severe ARDS. D'Ignazio et al. [27] reviewed two cases of severe blunt trauma patients with cervical spine and pelvis involvement who developed ARDS and were safely managed by prone positioning. Moreover, Kenn et al. [28] effectively treated a 34-week pregnant patient with blunt chest trauma and subsequent ARDS on prone positioning during 8 hours. Previously published data by Davis et al showed a decrease in mortality rate, fewer days on the ventilator and shorter length of hospital stay after using original prone kinetic therapy protocol (4 hours cycle per day use of kinetic therapy bed) in ARDS trauma patients Our data correlates well with that data and demonstrates a remarkable decrease in mortality rate in post-trauma critically ill patients. In contrast to the aforementioned study, we left our patients in the prone position until target physiological parameters $\left(\mathrm{PaO}_{2} / \mathrm{FiO}_{2}>200, \mathrm{FiO}_{2}<0.6\right)$ had been reached.

Application of PP might be complicated by loss of chest tubes, arterial and venous access catheters, and endotracheal or tracheostomy tubes in critically ill patients and, rarely, by development of peripheral nerve injuries, skin necrosis, or damage to the eyes [29-31]. The ICU physicians are unable to perform cardiopulmonary resuscitation in the event of cardiac arrest on PP [31]. In our study, the overall complications rate in trauma and non-trauma group was 10\% (Table 1), which correlates well with previously published data [25].

Our study has a number of limitations. The present study is retrospective and observational. We did not use a standard protocol. Thus, trauma group patients remained on prone position significantly longer than non-trauma persons. The patients' clinical data were collected during 1999-2005. We also planned to observe survived patients for a long-term outcome (during the next 5 years). However, we were not able to get a consistent outcome data from the patients' records [32].

\section{Conclusions}

In conclusion, our study showed clinical benefit by application of PP in the treatment of severe ARDS in post-trauma critically ill patients compared to non-trauma counterparts. We propose that a large multicenter prospective study would help to clarify the precise physiological mechanisms in which prone positioning application is advantageous in post-trauma critically ill patients.

\section{References}

1. Ashbaugh DG, Bigelow DB, Petty TL, Levine BE (2005) Ashbaugh DG, Bigelow DB, Petty TL, Levine BE. Acute respiratory distress in adults. The Lancet, Saturday 12 August 1967. Crit Care Resusc 7: 60-61.

2. Bernard GR, Artigas A, Brigham KL, Carlet J, Falke K, et al. (1994) The American-European Consensus Conference on ARDS. Definitions, mechanisms, relevant outcomes, and clinical trial coordination. Am J Respir Crit Care Med149: 818-824.

3. Pierrakos C, Karanikolas M, Scolletta S, Karamouzosd V, Velissaris D (2011) Acute Respiratory Distress Syndrome: Pathophysiology and Therapeutic Options. J Clin Med Res 4:7-16 
Citation: Brotfain E, Hur NBBN, Boniel N, Frenkel A, Koyfman L, et al. (2014) Prone Positioning Improves Oxygenation and Outcome of Trauma Patients with Severe Acute Respiratory Distress Syndrome (ARDS). J Trauma Treat 4: 228. doi:10.4172/2167-1222.1000228

4. ARDS Definition Task Force, Ranieri VM, Rubenfeld GD, Thompson BT, Ferguson ND, et al. (2012) Acute respiratory distress syndrome: the Berlin Definition. JAMA 307: 2526-2533.

5. Amato MB, Barbas CS, Medeiros DM, Magaldi RB, Schettino GP, et al. (1998) Effect of a protective-ventilation strategy on mortality in the acute respiratory distress syndrome. N Engl J Med 338: 347-354.

6. [No authors listed] (2000) Ventilation with lower tidal volumes as compared with traditional tidal volumes for acute lung injury and the acute respiratory distress syndrome. The Acute Respiratory Distress Syndrome Network. N Engl J Med 342: $1301-1308$

7. Gattinoni L, Pelosi P, Crotti S, Valenza F (1995) Effects of positive endexpiratory pressure on regional distribution of tidal volume and recruitment in adult respiratory distress syndrome. Am J Respir Crit Care Med 151: 1807-1814.

8. Blanch L, Mancebo J, Perez M, Martinez M, Mas A, et al. (1997) Short-term effects of prone position in critically ill patients with acute respiratory distress syndrome. Intensive Care Med 23: 1033-1039.

9. Vito Fanelli, Aikaterini Vlachou, Shirin Ghannadian, Umberto Simonetti, Arthur S. Slutsky, Haibo Zhang. Acute respiratory distress syndrome: new definition, current and future therapeutic options. J Thorac Dis 2013; 5:326-334

10. Ware LB (2006) Pathophysiology of acute lung injury and the acute respiratory distress syndrome. Semin Respir Crit Care Med 27: 337-349.

11. Taccone P, Pesenti A, Latini R, Polli F, Vagginelli F, et al. (2009) Prone-Supine II Study Group. Prone positioning in patients with moderate and severe acute respiratory distress syndrome: a randomized controlled trial. JAMA.30: 1977-1984.

12. Lemasson S, Ayzac L, Girard R, Gaillard S, Pavaday K, et al. (2006) Does gas exchange response to prone position predict mortality in hypoxemic acute respiratory failure? Intensive Care Med 32: 1987-1993.

13. Guerin C, Reignier J, Richard JC, Beuret P, Gacouin A, et al. (2013) Prone positioning in severe acute respiratory distress syndrome. N Engl J Med 368 2159-2168.

14. Voggenreiter G, Aufmkolk M, Stiletto RJ, Baacke MG, Waydhas C, et al. (2005) Prone positioning improves oxygenation in post-traumatic lung injury--a prospective randomized trial. J Trauma 59: 333-341.

15. Ware LB, Matthay MA (2000) The acute respiratory distress syndrome. N Eng J Med 342: 1334-1349.

16. Pelosi P, D'Onofrio D, Chiumello D, Paolo S, Chiara G, et al. (2003) Pulmonary and extrapulmonary acute respiratory distress syndrome are different. Eu Respir J Suppl 42: 48s-56s.

17. Bachofen M, Weibel ER (1977) Alterations of the gas exchange apparatus in adult respiratory insufficiency associated with septicemia. Am Rev Respir Dis 116: 589-615.
18. Bachofen M, Weibel ER (1982) Structural alterations of lung parenchyma in the adult respiratory distress syndrome. Clin Chest Med 3: 35-56.

19. Mure M, Lindahl SG (2001) Prone position improves gas exchange--but how? Acta Anaesthesiol Scand 45: 150-159.

20. Mure M, Glenny RW, Domino KB, Hlastala MP (1998) Pulmonary gas exchange improves in the prone position with abdominal distension. Am J Respir Crit Care Med 157: 1785-1790.

21. Gattinoni L, Tognoni G, Pesenti A, Taccone P, Mascheroni D, et al. (2001) Effect of prone positioning on the survival of patients with acute respiratory failure. N Engl J Med 345: 568-573.

22. Guerin C, Gaillard S, Lemasson S, Ayzac L, Girard R, et al. (2004) Effects of systematic prone positioning in hypoxemic acute respiratory failure: a randomized controlled trial. JAMA 292: 2379-2387.

23. Taccone P, Pesenti A, Latini R, Polli F, Vagginelli F, et al. (2009) Prone positioning in patients with moderate and severe acute respiratory distress syndrome: a randomized controlled trial. JAMA 302: 1977-1984.

24. Pelosi P, Brazzi L, Gattinoni L (2002) Prone position in acute respiratory distress syndrome. Eur Respir J 20: 1017-1028.

25. Offner PJ, Haenel JB, Moore EE, Biffl WL, Franciose RJ (2000) Complications of Prone Ventilation in Patients with Multisystem Trauma with Fulminant Acute Respiratory Distress Syndrome. J Trauma 48: 224-228.

26. Hale DF, Cannon JW, Batchinsky Al, Cancio LC, Aden JK (2012) Prone positioning improves oxygenation in adult burn patients with severe acute respiratory distress syndrome. J Trauma Acute Care Surg. 72: 1634-1639

27. D'Ignazio N, lannuzzi M, Colella V, Montisci A, De Sio A (2007) Postraumatic ARDS: how to place patients who may offer technical problems in a prone position. Minerva Anestesiol 73: 467-470.

28. Kenn S, Weber-Carstens S, Weizsaecker K, Bercker S (2009) Prone positioning for ARDS following blunt chest trauma in late pregnancy. Int $\mathrm{J}$ Obstet Anesth 18: $268-271$

29. Nahum A, Shapiro R (1996) Adjuncts to mechanical ventilation. Clin Chest Med 17: 491-511.

30. Fridrich $P$, Krafft $P$, Hochleuthner H, Mauritz W (1996) The effects of long-term prone positioning in patients with trauma-induced adult respiratory distress syndrome. Anesth Analg 83: 1206-1211.

31. Pappert D, Rossaint R, Slama K, Grüning T, Falke KJ (1994) Influence of positioning on ventilation-perfusion relationships in severe adult respiratory distress syndrome. Chest 106: 1511-1516.

32. Davis JW, Lemaster DM, Moore EC, Eghbalieh B, Bilello JF, et al. (2007) Prone ventilation in trauma or surgical patients with acute lung injury and adult respiratory distress syndrome: is it beneficial? J Trauma 62: 1201-1206. 